\title{
Pengaruh dari Direct Field Component pada Ruang Akustik dengan menggunakan SEA Model
}

\author{
Al Munawir ${ }^{1}$, Herri Darsan ${ }^{2}$, Murhaban $^{3}$ \\ ${ }^{1)}$ Jurusan Teknik Mesin, Fakultas Teknik Universitas Teuku Umar \\ ${ }^{2)}$ Jurusan Teknik Mesin, Fakultas Teknik Universitas Teuku Umar \\ 3)Jurusan Teknik Mesin, Fakultas Teknik Universitas Teuku Umar
}

Email: 1)almunawir@utu.ac.id, ${ }^{2}$ herri.darsan@utu.ac.id, ${ }^{3)}$ murhaban@utu.ac.id

\begin{abstract}
Statistical Energy Analysis (SEA) is a well-known method to analyze the flow of acoustic and vibration energy in a complex structure. This study investigates the application of the corrected SEA model in a non-reverberant acoustic space where the direct field component from the sound source dominates the total sound field rather than a diffuse field in a reverberant space which the classical SEA model assumption is based on. A corrected SEA model is proposed where the direct field component in the energy is removed and the power injected in the subsystem considers only the remaining power after the loss at first reflection. Measurement is conducted a box divided into two rooms separated by a partition with an opening where the condition of reverberant and non-reverberant can conveniently be controlled. In the case of a non-reverberant space where acoustic material was installed inside the wall of the experimental box, the signals are corrected by eliminating the direct field component in the measured impulse response. Using the corrected SEA model, comparison of the coupling loss factor (CLF) with the theory shows good agreement.
\end{abstract}

Keyword: Statistical Energy Analysis (SEA), coupling loss factor (CLF), acoustic space.

\section{PENDAHULUAN}

Salah satu metode yang sudah terkenal untuk memprediksi noise dan vibration adalah Statistical Energy Analysis (SEA). SEA merupakan suatu metode untuk menganalisa aliran akustik dan energi getaran dalam struktur yang kompleks dan di aplikasikan dalam rentang frekuensi yang tinggi dimana energi diperhitungkan secara 'statistically'. SEA sudah banyak digunakan dalam pesawat terbang, mobil, kereta api[1], dalam dunia industri dan juga bangunan akustik[2]. Pada $S E A$, stuktur di bagi dalam beberapa subsistem dan aliran energi antara subsistem di jelaskan dengan istilah coupling loss factor (CLF).

Kalkulasi $C L F$ antara ruangan dan rongga dengan metode $S E A$ telah di lakukan oleh Price dan Crocker [3] dengan mengasumsikan bahwa transmisi dari ruangan ke rongga sama halnya dengan transmisi dari ruangan ke ruangan. Ahmida dan Arruda juga telah memperhitungkan CLF dengan menggunakan Spectra Element Method (SEM).

Metode SEA mengasumsikan bahwa energi dalam suatu subsistem harus tersebar secara merata dalam suatu subsitem yang disebut juga dengan kondisi reverberant field [4]. Pada ruang akustik yang telah terpasang material akustik akan menyebabkan berkurangnya kondisi reverberant field dan akan didominasi dengan kondisi direct field. Hal ini menyebabkan prinsip kerja untuk SEA klasik tidak dapat memprediksikan dengan benar [5]. 
Dalam artikel ini, suatu pengembangan metode baru dari SEA model akan dihasilkan. Teknik pengembangan dari SEA model ini dengan cara menghilangkan bagian dari direct field dari total energi suara.

\section{METODE PENELITIAN}

\subsection{Experimental SEA}

Power Injection Method (PIM) adalah salah satu teknik yang digunakan untuk menentukan parameter SEA, yaitu coupling loss factor(CLF) dan damping loss factor(DLF) [6]. Dengan membagikan sistem ke dalam $N$ subsistem dan setiap subsistem diinjeksikan input power $P_{\text {in }}$ seperti yang ditunjukkan pada gambar 1, maka persamaan dasar dari SEA di berikan dengan:

$$
P_{i n, i}=\omega \eta_{i} E_{i}+\sum_{\substack{j=1 \\ j \neq 1}}^{N} \omega \eta_{i j} E_{i}-\sum_{\substack{j=1 \\ j \neq 1}}^{N} \omega \eta_{j i} E_{j}
$$

Dimana $\omega$ adalah frekuensi angular, $E$ adalah energi dalam subsistem, $\eta_{i}$ adalah damping loss factor (DLF) dalam subsystem, $\eta_{i j}$ adalah coupling loss factor (CLF).

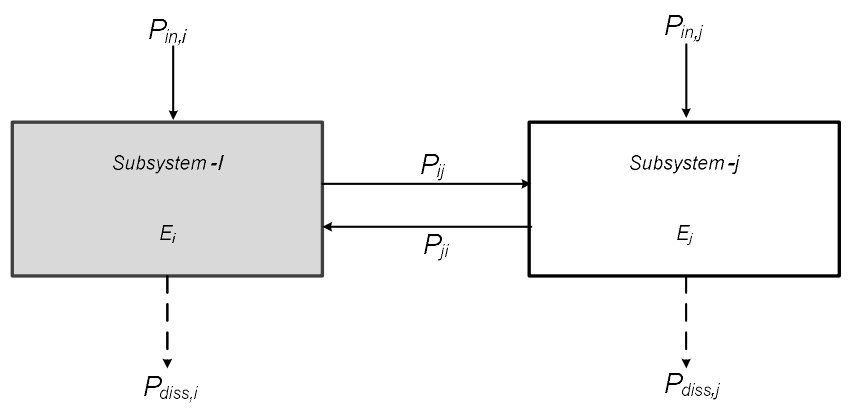

Gambar 1. Diagram skematik dari SEA Model

Untuk sistem yang terdiri hanya dua subsistem, pers. (1) dapat ditulis dalam bentuk matriks:

$\left\{\begin{array}{l}P_{i n, 1} \\ P_{i n, 2}\end{array}\right\}=\omega\left[\begin{array}{cc}\eta_{1}+\eta_{12} & -\eta_{21} \\ -\eta_{12} & \eta_{2}+\eta_{21}\end{array}\right]\left\{\begin{array}{l}E_{1} \\ E_{2}\end{array}\right\}$

Untuk langkah pertama, subsistem-1 di injeksikan input power $\left(P_{I}{ }^{(I)}\right)$, sehinggga pers. (2) dapat ditulis:

$\left\{\begin{array}{c}P_{1}^{(1)} \\ 0\end{array}\right\}=\omega\left[\begin{array}{cc}\eta_{1}+\eta_{12} & -\eta_{21} \\ -\eta_{12} & \eta_{2}+\eta_{21}\end{array}\right]\left\{\begin{array}{l}E_{1}{ }^{(1)} \\ E_{2}{ }^{(2)}\end{array}\right\}$

Dimana $E_{1}{ }^{(l)}$ dan $E_{2}{ }^{(l)}$ adalah energi yang terukur di dalam subsistem-1 dan subsistem-2 yang disebabkan dengan input power dalam subsistem-1.

Untuk langkah kedua, subsistem-2 di injeksikan input power $\left(P_{2}{ }^{(2)}\right)$, sehingga pers. (2) juga dapat ditulis: 
Jurnal Mekanova

Vol 5 No. 2, Oktober 2019

ISSN : 2502-0498

$\left\{\begin{array}{c}0 \\ P_{2}^{(2)}\end{array}\right\}=\omega\left[\begin{array}{cc}\eta_{1}+\eta_{12} & -\eta_{21} \\ -\eta_{12} & \eta_{2}+\eta_{21}\end{array}\right]\left\{\begin{array}{l}E_{1}^{(2)} \\ E_{2}^{(2)}\end{array}\right\}$

Dimana $E_{1}{ }^{(2)}$ dan $E_{2}^{(2)}$ adalah energi yang terukur di dalam subsistem-1 dan subsistem-2 yang disebabkan dengan input power dalam subsistem-2.

Kombinasi pers. (3) dan (4), akan menghasilkan:

$\left[\begin{array}{cc}P_{1}^{(1)} & 0 \\ 0 & P_{2}^{(2)}\end{array}\right]=\omega\left[\begin{array}{cc}\eta_{1}+\eta_{12} & -\eta_{21} \\ -\eta_{12} & \eta_{2}+\eta_{21}\end{array}\right]\left[\begin{array}{cc}E_{1}^{(1)} & E_{1}^{(2)} \\ E_{2}^{(1)} & E_{2}^{(2)}\end{array}\right]$

Dengan demikian, damping loss factor (DLF) dan coupling loss factor (CLF)dapat ditentukan sebagai berikut:

$\left[\begin{array}{cc}\eta_{1}+\eta_{12} & -\eta_{21} \\ -\eta_{12} & \eta_{2}+\eta_{21}\end{array}\right]=\frac{1}{\omega}\left[\begin{array}{cc}P_{1}^{(1)} & 0 \\ 0 & P_{2}^{(2)}\end{array}\right]\left[\begin{array}{cc}E_{1}^{(1)} & E_{1}^{(2)} \\ E_{2}^{(1)} & E_{2}^{(2)}\end{array}\right]^{-1}$

Coupling loss factor(CLF) secara teori diperoleh dengan menggunakan persamaan (Price dan Crocker, 1969):

$\eta_{12}=\frac{\tau_{12} c S}{4 \omega V}$

Dimana $\tau_{12}$ adalah koefisien transmisi antara subsistem 1 dan 2, $S$ adalah luas permukaan coupling, $V$ adalah volume dalam subsistem dan $c$ adalah kecepatan suara di udara.

Di dalam suatu ruang akustik yang tertutup, total energi suara yang diberikan merupakan penjumlahan dari direct field yang di hasilkan dari sumber suara dan reverberant field yang di hasilkan dari suara pantulan sebagaimana yang diilustrasikan pada gambar 2. Pernyataan ini dapat dirumuskan:

$E=E_{d i r}+E_{\text {rev }}$

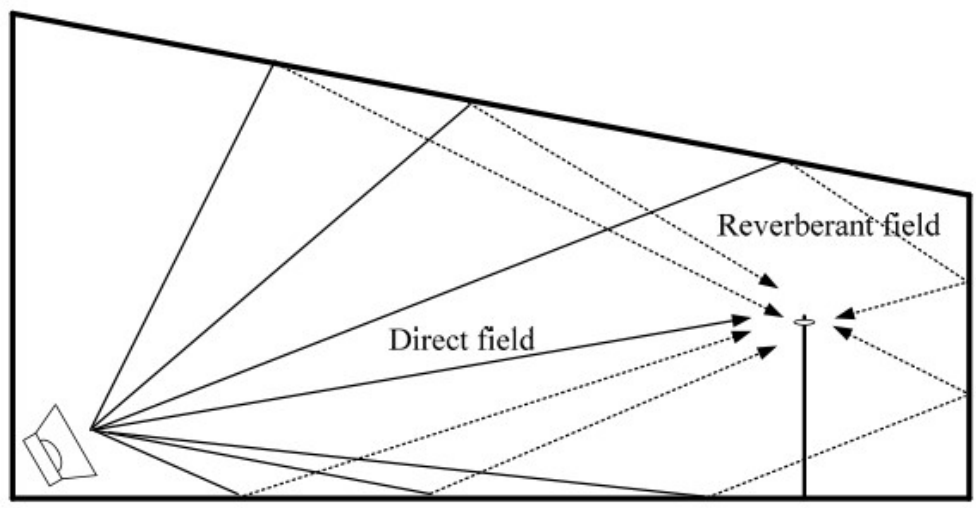

Gambar 2. Ilustrasi dari direct dan reverberant field dalam ruang akustik

Jika dalam ruangan akustik tersebut dipasang material absorben, maka komponen direct field mendominasi dari total energi suara dalam ruangan. Untuk kondisi seperti ini dimana SEA model 
tidak dapat mendeteksi komponen direct field. Oleh karena itu, menghilangkan komponen direct field dari total energi menjadi sangat penting. Dalam hal ini, pers (1) dapat di tulis menjadi:

$$
P_{i n, i}\left(1-\bar{\alpha}_{i}\right)=\omega \eta_{i} E_{r e v, i}+\sum_{\substack{j=1 \\ j \neq 1}}^{N} \omega \eta_{i j} E_{r e v, i}-\sum_{\substack{j=1 \\ j \neq 1}}^{N} \omega \eta_{j i} E_{r e v, j}
$$

Dimana $\bar{\alpha}_{i}$ adalah rata-rata koefisien absorben dalam subsistem dan $E_{r e v, i}$ adalah energi dari komponen reverberant field setelah menghilangkan komponen direct field dari total energi. Model SEA ini telah digunakan oleh Ribeiro dan Smith [7] untuk mengembangkan metode prediksi kebisingan di ruang akustik yang besar dimana kontribusi direct field ditentukan dengan mengasumsikan perambatan suara menjauh dari sumber suara.

Komponen direct field dapat diindentifikasikan pada pengukuran impuls respon yang di peroleh dari invers Fast Fourier Transform (FFT) ke pengukuran Frequency Response Function (FRF) dalam subsistem. Fitur impuls respon terdiri dari puncak awal yang disebabkan oleh komponen direct field dan diikuti oleh puncak lainnya sebagai bagian dari sinyal pantulan yang disebabkan oleh komponen reverberant field. Dengan menerapkan aplikasi sederhana dari window function, komponen direct field dihilangkan dan selanjutnya FRF tanpa direct field komponen dapat diperoleh lagi dengan menerapkan kembali FFT. Gambar 3 menunjukkan diagram metodelogi untuk menghilang komponen direct field.

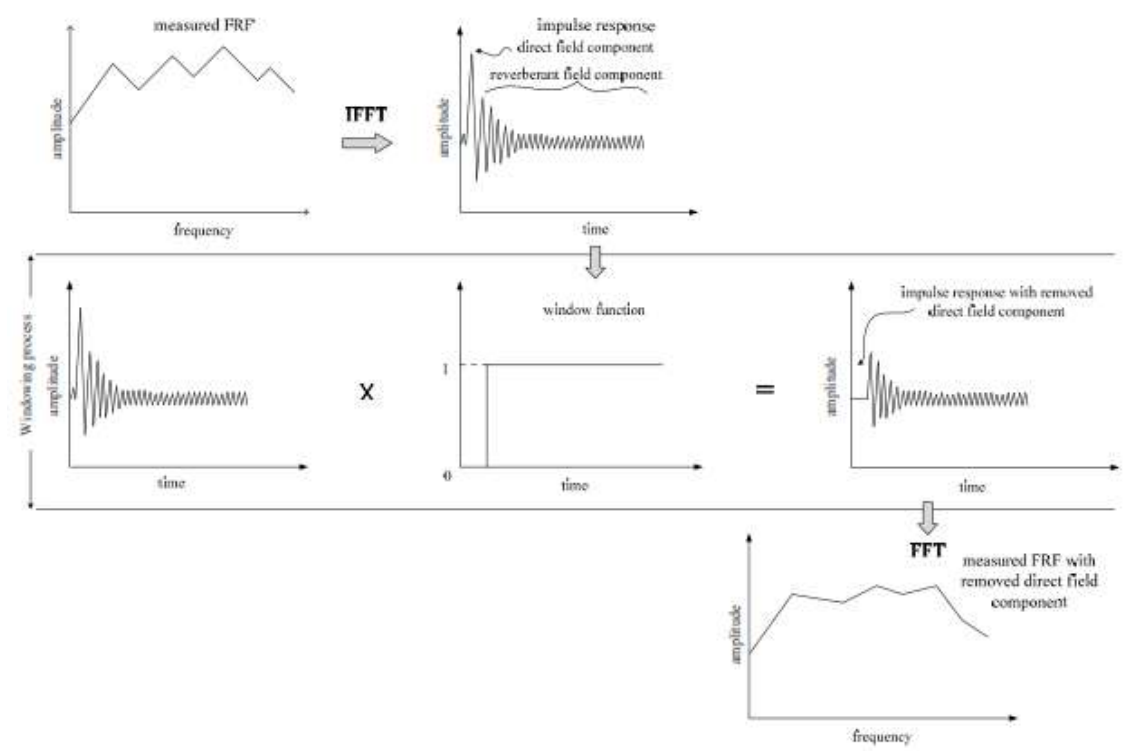

Gambar 3. Diagram metodelogi untuk menghapus bagian direct field.

\subsection{Measurement}


Jurnal Mekanova

Vol 5 No. 2, Oktober 2019

ISSN : 2502-0498

Sebuah couple box di bangun untuk menvalidasi pengembangan dari SEA Model. Couple box terbuat dari plat aluminium dengan ketebalan $1 \mathrm{~mm}$ yang masing-masing memiliki volume sekitar $0,18 \mathrm{~m}^{3}$ dan dipisahkan oleh sebuah partisi yang terbuat dari bahan yang sama dengan area pembuka $150 \mathrm{x}$ $150 \mathrm{~mm}$. Gambar 4 menunjukkan pengaturan pengukuran pada couple box untuk eksperimen SEA Model. Untuk kondisi tidak bergema, spons dipasang pada dinding sebagai material absorber.

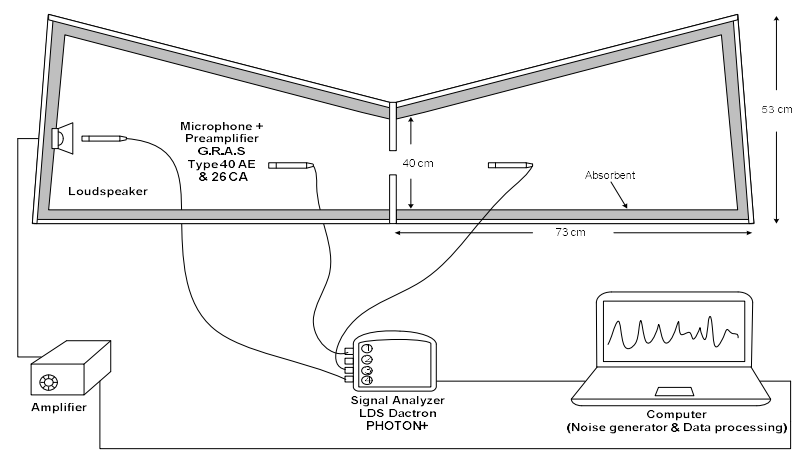

Gambar 4. Pengaturan pengukuran untuk SEA Model

Pengukuran pertama dilakukan saat couple box tanpa dipasang spons (kondisi bergema) dan kondisi kedua dilakukan saat coupled box dipasang spons (kondisi tidak bergema). Kedua box dipisahkan oleh sebah partisi yang terbuat dari bahan yang sama dengan ruang pembuka berukuran $150 \times 150$ mm tepat ditengahnya.

\section{HASIL DAN PEMBAHASAN}

Gambar 5(a) menunjukkan hasil impulse respons pada ruang gema dan Gambar 5(b) menunjukkan hasil impulse respons pada ruang tidak bergema (material absorber). Bagian direct field dapat dilihat pada suatu puncak yang tinggi pada gambar 5(b). Selanjutnya dengan menggunakan window function, bagian direct field dihilangkan, hal ini dapat dilihat pada gambar 6 .

(a)

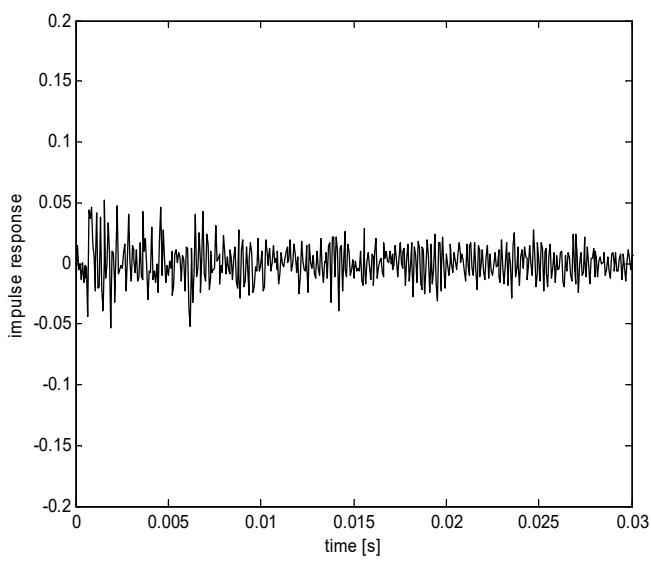

(b)

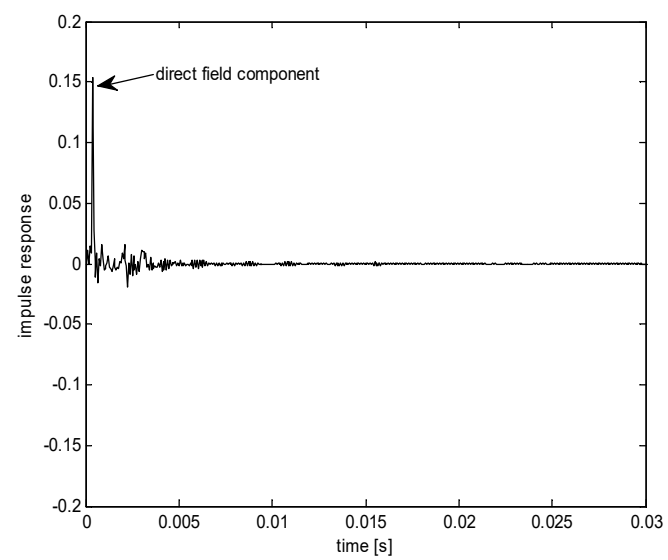

Gambar 5. Pengukuran impulse respons (a) kondisi bergema dan (b) kondisi tidak bergema (material absorber) 


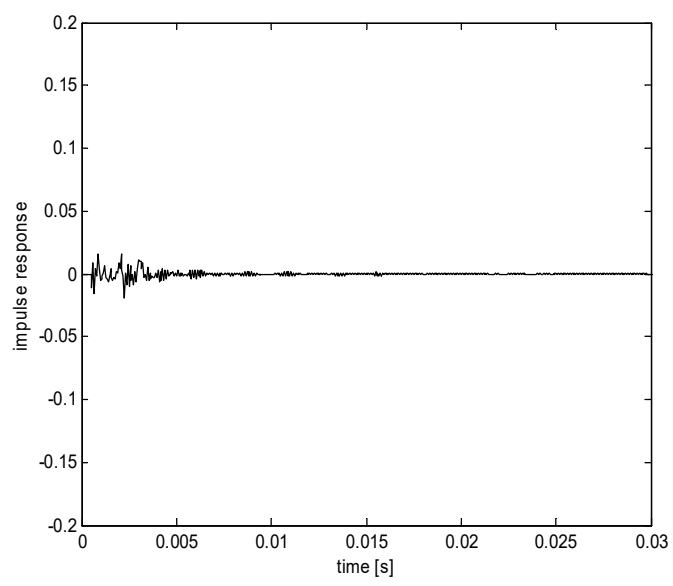

Gambar 6. Pengukuran impulse di dalam subsistem setelah komponen direct field di hilangkan

Gambar 7 (a) menunjukkan coupling loss factor dengan menggunakan pers. 7 sebelum bagian direct field dihilangkan. Ini menunjukkan pengukuran coupling loss factor terlalu tinggi di banding kan dengan teori. Gambar 7 (b) menunjukkan coupling loss factor setelah direct field dihilangkan, ini menunjukkan ada kesesuaian dengan teori di atas $2 \mathrm{kHz}$.

(a)

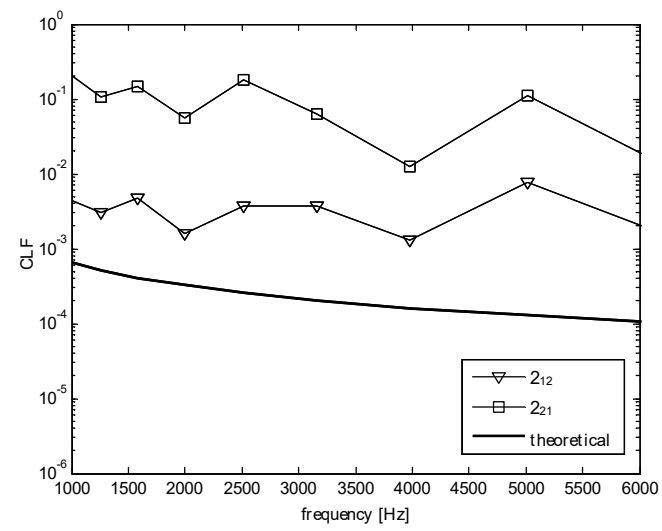

(b)

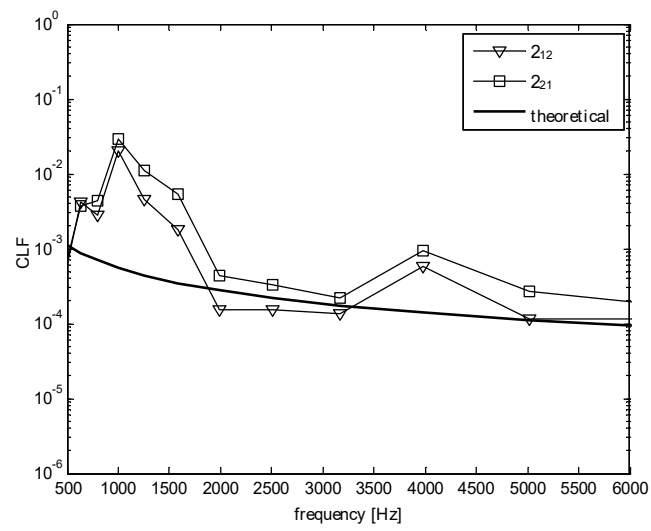

Gambar 7. Coupling loss factor di dalam ruang tidak bergema (a) sebelum dan (b) sesudah bagian direct field dihilangkan

\section{KESIMPULAN}

Sebuah pendekatan baru dalam Statistical Energy Analysis (SEA) telah digunakan untuk menyelesaikan masalah pemodelan dalam ruang akustik tidak bergema dimana bagian direct field mendominasi dari total energi dalam ruang akustik. Model ini dengan menghilangkan bagian direct field dari total energi suara dalam subsistem dimana SEA klasik tidak dapat menprediksi dengan benar bagian direct field. Pengukuran ini dilakukan di ruang eksperimen (couple box) dengan memasang material absorber (spons) pada dinding box. Pengukuran ini 
menghasilkan suatu penyesuaian dari coupling loss factor antara $S E A$ yang baru dengan teori dibandingkan dengan $S E A$ klasik yang menghasil perbedaan yang jauh dengan teori.

\section{References}

[1] J. Forssen, S. Tober, A. C. Corakci, A. Frid and W. Kropp, Modelling the interior sound field of a railway vehicle using statistical energy analysis, Applied Acoustic, 73(2012), 301-311.

[2] M. J. Kim and J. Y. Shon, Prediction and evaluation of impact sound transmission in apartment building structures by statistical energy analysis, Applied Acoustic, 62(2001), 601-616.

[3] A. J. Price and M. J. Crocker, Sound transmission using statistical energy analysis, Journal of Sound and Vibration, 9(1969), 469-486.

[4] K. M. Ahmida and J. F. F. Arruda, Estimation of the Statistical Energy Analysis (SEA) coupling loss factors by means of spectral element modeling, Journal of the Braz. Soc. of Mech. Sci. and Eng, 3(2003), 259-263.

[5] K. Renji, P. S. Nair, and S. Narayanan. Non-resonant response using statistical energy analysis, Journal of Sound and Vibration, 241(2001), 253-270.

[6] R. Ribeiro and M. G. Smith, Use of SEA to model the sound filed in large acoustic spaces, Forum Acousticum, (2005), 79-84.

[7] R. H. Lyon and G. D. DeJong, Theory and application of statistical energy analysis. 2nd Ed. Butterworth-Heinemann.(1995). 